\title{
CAPABILITIES OF THE NEW SUERC 5MV AMS FACILITY FOR ${ }^{14} \mathrm{C}$ DATING
}

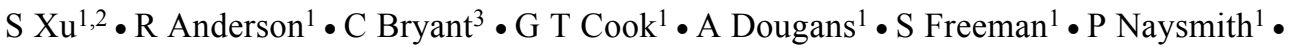 \\ C Schnabel ${ }^{1} \bullet \mathrm{E} \mathrm{M} \mathrm{Scott}^{4}$
}

\begin{abstract}
A new National Electrostatic Corporation (NEC) 5MV accelerator mass spectrometer became operational at the Scottish Universities Environmental Research Centre (SUERC) in July 2002. It has 2 Cs sputter negative ion sources: a 134-sample source (S1) for the routine measurement of all species, and a hybrid source (S2) with 40 spaces for radiocarbon measurements with either graphite or $\mathrm{CO}_{2}$ samples. A number of performance tests on graphite samples have been carried out on both sources. A precison of better than $0.3 \%$ is feasible for modern samples on a routine basis. The ${ }^{14} \mathrm{C}$ background of the machine and the graphite preparation process blank are $0.04 \pm 0.01$ and $0.16 \pm 0.05 \mathrm{pMC}$, respectively, indicating that ${ }^{14} \mathrm{C}$ dating back to $\sim 50 \mathrm{kyr} \mathrm{BP}$ is possible. The normalized ${ }^{14} \mathrm{C}$ values for a series of reference materials agree well with the IAEA, TIRI, and FIRI consensus values. Routine measurement of ${ }^{14} \mathrm{C}$ has been underway since May 2003. Preliminary results of performance tests on the $\mathrm{CO}_{2}$ gas ion source are also reported.
\end{abstract}

\section{INTRODUCTION}

A new NEC 5MV accelerator mass spectrometer (AMS) was installed at the Scottish Universities Environmental Research Centre in July 2002 (Freeman et al., forthcoming a, b). The SUERC spectrometer is equipped with 2 ion sources. One source (S1) accommodates up to 134 samples and is intended for the routine measurement of all species $\left({ }^{10} \mathrm{Be},{ }^{14} \mathrm{C},{ }^{26} \mathrm{Al},{ }^{36} \mathrm{Cl}\right.$, and $\left.{ }^{129} \mathrm{I}\right)$, while the other 40 -sample source (S2) is a hybrid ion source for radiocarbon measurements with either graphite or $\mathrm{CO}_{2}$ samples. This paper presents the results for performance tests on graphite samples using both ion sources and also includes preliminary results for performance tests on $\mathrm{CO}_{2}$ samples.

\section{${ }^{14} \mathrm{C}$ Performance Tests on Solid Samples}

A number of performance tests for ${ }^{14} \mathrm{C}$ have been performed for the SUERC AMS using the 2 ion sources. The tests have included the study of parameters such as precision, accuracy of normalization, background levels, as well as sample lifetime and throughput. The graphite targets were prepared by the 2 SUERC-hosted ${ }^{14} \mathrm{C}$ laboratories, NERC lab and SUERC lab, based on the method given by Slota et al. (1987). Each target is composed of 1-2 mg C mixed with 1-2 mg Fe powder. The injection energy of the extracted negative ions was $66 \mathrm{KeV}$. The measurements were performed at a terminal voltage: $4.5 \mathrm{MV}$; charge state: +4 ; total ion energy: $22.5 \mathrm{MeV}$; and Ar stripper gas pressure: 7-8 Torr. Each sample was scheduled for 5 measurements. For an individual measurement, the modern samples (e.g. oxalic acid and barley mash) were determined until statistical uncertainty reached $0.5 \%\left(40,000{ }^{14} \mathrm{C}\right.$ counts), while the background graphite samples were counted for 9000 cycles (about $15 \mathrm{~min}$ ). However, some samples were completed early if an assigned target value, based on the mean standard deviation of the 3 most recent measurements $(0.5 \%$ for the modern samples and $10 \%$ for background samples), was reached.

For data reduction, an off-line data reduction program calculated 4 values from the measurement data: (1) mean sample isotopic ratio (a weighted average); (2) statistical uncertainty; (3) standard deviation of the mean (SDOM) uncertainty of isotopic ratios; and (4) $\chi^{2}$ statistics. The program uses the $\chi^{2}$ statistics to determine if the scatter of the measured isotopic ratios about the average is con-

${ }^{1}$ Scottish Universities Environmental Research Centre, East Kilbride G75 0QF, United Kingdom.

${ }^{2}$ Corresponding author. Email: s.xu@suerc.gla.ac.uk.

${ }^{3}$ NERC Radiocarbon Laboratory, East Kilbride G75 0QF, United Kingdom.

${ }^{4}$ Department of Statistics, University of Glasgow, Glasgow G12 8QW, United Kingdom.

(C) 2004 by the Arizona Board of Regents on behalf of the University of Arizona Proceedings of the 18th International Radiocarbon Conference, edited by N Beavan Athfield and R J Sparks RADIOCARBON, Vol 46, Nr 1, 2004, p 59-64 
sistent with the counting statistic uncertainties of the measurements. Briefly, a sample passes the $\chi^{2}$ test if its $\chi^{2}$ statistics are less than or equal to the $5 \% \chi^{2}$ value which varies with degree of freedom, and fails the $\chi^{2}$ test if its $\chi^{2}$ statistics are greater than the $5 \% \chi^{2}$ value. For samples that pass the $\chi^{2}$ test, the program sets the sample ratio equal to the weighted average of the measurement ratios and its uncertainty to the statistical uncertainty. However, for samples that fail the $\chi^{2}$ test, the simple, not the weighted, average of the measurement ratios and SDOM are used for the sample ratio and its uncertainty, respectively, in subsequent calculations. Moreover, in this study, $\delta^{13} \mathrm{C}$ values and uncertainties calculated from measured ${ }^{13} \mathrm{C} /{ }^{12} \mathrm{C}$ ratios were used for isotope fractionation correction for ${ }^{14} \mathrm{C}$ activity or age calculations.

\section{Acceptance Tests}

Three oxalic acid standards (OxII) and 3 barley mash samples were used for precision acceptance tests on source S2 (Table 1). In this batch, the ${ }^{12} \mathrm{C}^{-}$currents were between 50 and $58 \mu \mathrm{A}$, with an accelerator $4+$ particle transmission of $56 \%$. The standard deviation $(1 \sigma)$ of the ${ }^{13} \mathrm{C} /{ }^{12} \mathrm{C}$ and ${ }^{14} \mathrm{C} /{ }^{12} \mathrm{C}$ ratios of the individual OxII sample was $0.2-0.4 \%$ and $0.2-0.3 \%$, respectively. The latter is identical to the statistical uncertainty of $0.2-0.3 \%$. Averaging the 3 OxII samples gives a precision of $0.15 \%$ and $0.13 \%$ for the ${ }^{13} \mathrm{C} /{ }^{12} \mathrm{C}$ and ${ }^{14} \mathrm{C} /{ }^{12} \mathrm{C}$ ratios, respectively. These results showed better than $3 \%$ precision on the individual and average values. In the case of the barley mash samples, precision on the ${ }^{13} \mathrm{C} /{ }^{12} \mathrm{C}$ and ${ }^{14} \mathrm{C} /{ }^{12} \mathrm{C}$ ratios of the individual samples was $0.2 \%$ and $0.4 \%$, respectively. These 3 samples yielded better than $3 \%$ precision not only on the average ${ }^{14} \mathrm{C} /{ }^{12} \mathrm{C}$ ratio $(0.26 \%)$ but also on the normalization value $(0.27 \%)$. It should be pointed out that a repeat of the test at high currents (about $80 \mu \mathrm{A})$, but with reduced accelerator $4+$ particle transmission $(50 \%)$, gave similar results.

The same performance tests were also carried out on source S1. The negative currents extracted from S1 source were 30-35 $\mu \mathrm{A}$, slightly lower than those from S2. The average accelerator 4+ particle transmission was 56\%. Following the same experimental conditions used in $\mathrm{S} 2$, the $\mathrm{S} 1$ source gave similar precision for the ${ }^{14} \mathrm{C} /{ }^{12} \mathrm{C}$ and ${ }^{13} \mathrm{C} /{ }^{12} \mathrm{C}$ ratios as observed in $\mathrm{S} 2$ source. Therefore, the acceptance tests demonstrated that our new AMS system can perform high-precision measurements of ${ }^{14} \mathrm{C} /{ }^{12} \mathrm{C}$ and ${ }^{13} \mathrm{C} /{ }^{12} \mathrm{C}$ ratios.

\section{System Background}

A natural graphite sample (Alfa Aesar graphite powder 100 mesh with a purity of 99.9995\%) was measured to assess machine ${ }^{14} \mathrm{C}$ background, while doublespar (TIRI F) and an interglacial wood (BK-ow) were used to assess system contamination. These materials were always placed adjacent to an OxII or modern sample to monitor any possible cross-contamination between the sample targets. The observed ${ }^{14} \mathrm{C} /{ }^{12} \mathrm{C}$ ratios of Alfa Aesar graphite were generally less than $5 \times 10^{-16}$, corresponding to $0.03 \mathrm{pMC}$ (Table 1), which is equivalent to a ${ }^{14} \mathrm{C}$ age of $64 \mathrm{kyr}$. This result clearly shows that machine background and source cross-contamination are negligible.

A large volume of $\mathrm{CO}_{2}$ was produced from doublespar and interglacial wood to minimize contamination during $\mathrm{CO}_{2}$ production. From this volume, sub-samples of $\mathrm{CO}_{2}$ equivalent to $1-2 \mathrm{mg} \mathrm{C}$ were graphitized. The doublespar yielded $0.16 \pm 0.06 \mathrm{pMC}$, while the interglacial wood yielded $0.16 \pm 0.05 \mathrm{pMC}$. This indicates that a slight contamination has occurred during the graphite target preparation process. Based on the calculation given by Donahue et al. (1990), a ${ }^{14} \mathrm{C}$ dating limit of 51 kyr was obtained. 
Table 1 Precision of ${ }^{14} \mathrm{C}$ acceptance test measurement on 19 May 2003 (Source S2) ${ }^{\mathrm{a}}$.

\begin{tabular}{|c|c|c|c|c|c|c|}
\hline Materials & $\begin{array}{l}{ }^{12} \mathrm{C}^{-} \\
(\mu \mathrm{A})\end{array}$ & $\begin{array}{l}{ }^{14} \mathrm{C} \text { counts } \\
\text { (atoms) }\end{array}$ & $\begin{array}{l}{ }^{13} \mathrm{C} /{ }^{12} \mathrm{C} \\
\left(\times 10^{-2}\right)\end{array}$ & $\begin{array}{l}\delta^{13} \mathrm{C} \\
(\%)\end{array}$ & $\begin{array}{l}{ }^{14} \mathrm{C} /{ }^{12} \mathrm{C}^{\mathrm{b}} \\
\left(\times 10^{-12}\right)\end{array}$ & $\begin{array}{l}{ }^{14} \mathrm{C} \\
(\mathrm{pMC})\end{array}$ \\
\hline Oxalic acid & 50 & 121,338 & $1.0641 \pm 0.0021$ & & $1.2094 \pm 0.0035$ & \\
\hline Oxalic acid & 52 & 121,941 & $1.0667 \pm 0.0045$ & & $1.2074 \pm 0.0035$ & \\
\hline Oxalic acid & 53 & 248,613 & $1.0643 \pm 0.0021$ & & $1.2063 \pm 0.0025$ & \\
\hline Mean for above 3 samples & & & $1.0650 \pm 0.0016$ & $-17.8 \pm 1.5$ & $1.2077 \pm 0.0016$ & $134.07 \pm 0.27$ \\
\hline Relative deviation (\%) & & & 0.15 & & 0.13 & \\
\hline Statistical uncertainty (\%) & & 0.14 & & & & \\
\hline Barley mash (BBM-48) & 50 & 122,202 & $1.0557 \pm 0.0019$ & $-26.4 \pm 1.4$ & $1.0426 \pm 0.0043$ & $115.78 \pm 0.60$ \\
\hline Barley mash (BBM-49) & 55 & 122,557 & $1.0587 \pm 0.0023$ & $-23.5 \pm 1.1$ & $1.0474 \pm 0.0039$ & $116.31 \pm 0.56$ \\
\hline Barley mash (BBM-50) & 58 & 122,717 & $1.0584 \pm 0.0021$ & $-23.8 \pm 1.5$ & $1.0426 \pm 0.0044$ & $115.77 \pm 0.61$ \\
\hline Mean for above 3 samples & & & $1.0573 \pm 0.0014$ & $-24.6 \pm 1.6$ & $1.0442 \pm 0.0028$ & $115.95 \pm 0.31$ \\
\hline Relative deviation (\%) & & & 0.13 & & 0.26 & 0.27 \\
\hline Alfa Aesar graphite & 50 & 134 & $1.0781 \pm 0.0016$ & & $0.00030 \pm 0.00003$ & $0.034 \pm 0.003$ \\
\hline
\end{tabular}

aNo data blocks were rejected.

${ }^{\mathrm{b}} \mathrm{No}$ background was subtracted and isotope fractionation was corrected using AMS $\delta^{13} \mathrm{C}$.

\section{${ }^{14}$ C Accuracy}

A series of well-characterized samples were measured to assess the accuracy of the ${ }^{14} \mathrm{C}$ measurements. These included IAEA C6 (ANU sucrose) and barley mash (TIRI A) to assess accuracy and precision of modern samples, while IAEA C2, C5, C7, C8, Belfast cellulose (FIRI I), and 96 humin (in-house standard) provided samples with a range of ages for similar tests. The results showed that most of the individual measurements agreed with the consensus values within the $1-\sigma$ uncertainty margin. In Table 2, average measured ${ }^{14} \mathrm{C}$ values are compared with the consensus values. It is clear that the relative ${ }^{14} \mathrm{C}$ age differences between the measured and the consensus values are all in the range from -0.4 to $0.5 \%$.

Table 2 Normalization of reference materials.

\begin{tabular}{|c|c|c|c|c|c|c|c|}
\hline \multirow[b]{2}{*}{ Code } & \multirow[b]{2}{*}{ Materials } & \multirow[b]{2}{*}{$\begin{array}{l}\mathrm{Nr} \text { of } \\
\text { samples }\end{array}$} & \multicolumn{2}{|c|}{ Measured ${ }^{14} \mathrm{C}$} & \multicolumn{2}{|c|}{ Consensus ${ }^{14} \mathrm{C}^{\mathrm{a}}$} & \multirow[b]{2}{*}{$\begin{array}{l}\text { Relative } \\
\text { difference (\%) }\end{array}$} \\
\hline & & & $\begin{array}{l}\text { Activity } \\
\text { (pMC) }\end{array}$ & $\begin{array}{l}\text { Age } \\
\text { (BP) }\end{array}$ & $\begin{array}{l}\text { Activity } \\
\text { (pMC) }\end{array}$ & $\begin{array}{l}\text { Age } \\
\text { (BP) }\end{array}$ & \\
\hline IAEA C6 & Sucrose & 5 & $150.31 \pm 0.39$ & - & $150.61 \pm 0.11$ & - & -0.20 \\
\hline TIRI A & Barley mash & 25 & $116.35 \pm 0.52$ & - & $116.35 \pm 0.0084$ & - & 0.00 \\
\hline IAEA C7 & Oxalic acid & 3 & $49.65 \pm 0.29$ & - & $49.54 \pm 0.13$ & - & 0.22 \\
\hline IAEA C2 & Travertine & 3 & $41.13 \pm 0.27$ & - & $41.14 \pm 0.03$ & - & -0.02 \\
\hline IAEA C5 & Wood & 4 & $23.15 \pm 0.11$ & - & $23.05 \pm 0.02$ & - & 0.43 \\
\hline IAEA C8 & Oxalic acid & 3 & $15.11 \pm 0.08$ & - & $15.03 \pm 0.18$ & - & 0.53 \\
\hline FIRI I & Belfast cellulose & 16 & - & $4494 \pm 35$ & - & $4485 \pm 6$ & 0.20 \\
\hline $96 \mathrm{H}$ & Humin & 18 & - & $3365 \pm 37$ & - & $3379 \pm 66$ & -0.41 \\
\hline TIRI F & Doublespar & 41 & $0.16 \pm 0.06$ & 52,000 & $0.180 \pm 0.006$ & - & - \\
\hline BK-ow & Interglacial wood & 23 & $0.16 \pm 0.05$ & 52,000 & - & - & - \\
\hline Alfa Aesar & Natural graphite & 22 & $0.04 \pm 0.01$ & 63,000 & - & - & - \\
\hline
\end{tabular}

${ }^{a}$ Consensus values for IAEA C2, C5, and C6 are from Rozanski et al. (1992), IAEA C7 and C8 from Clercq et al. (1998), TIRI A and TIRI F from Gulliksen and Scott (1995), and FIRI I from Scott (2003).

In addition to the performance tests listed above, $\delta^{13} \mathrm{C}$ values measured with the SUERC AMS were compared with those determined using dual inlet mass spectrometers (VG OPTIMA and MICROMASS SIRA 10). AMS $\delta^{13} \mathrm{C}$ values were obtained from the AMS-measured ${ }^{13} \mathrm{C} /{ }^{12} \mathrm{C}$ ratio of the sample normalized to the measured ${ }^{13} \mathrm{C} /{ }^{12} \mathrm{C}$ ratio of the OxII standard materials. Figure 1 shows a comparison of $\delta^{13} \mathrm{C}$ values from the 2 methods for a typical batch of measurements. In this batch, the 
AMS $\delta^{13} \mathrm{C}$ values for 102 of the total of 104 samples agreed with the dual inlet MS $\delta^{13} \mathrm{C}$ values within $\pm 5 \%$, which brings about a maximum of $\pm 40 \mathrm{yr}$ difference when applying the $\delta^{13} \mathrm{C}$ correction to the ${ }^{14} \mathrm{C} /{ }^{13} \mathrm{C}$ ratio in ${ }^{14} \mathrm{C}$ age calculation. At present, the reason for the difference is not quite clear and more precise measurements over a long term need to be done; however, we expect that the AMS $\delta^{13} \mathrm{C}$ values can potentially be used for isotopic fractionation correction of the ${ }^{14} \mathrm{C}$ ages, as has previously only been used in very a few AMS laboratories (e.g. Bonani et al. 1987).

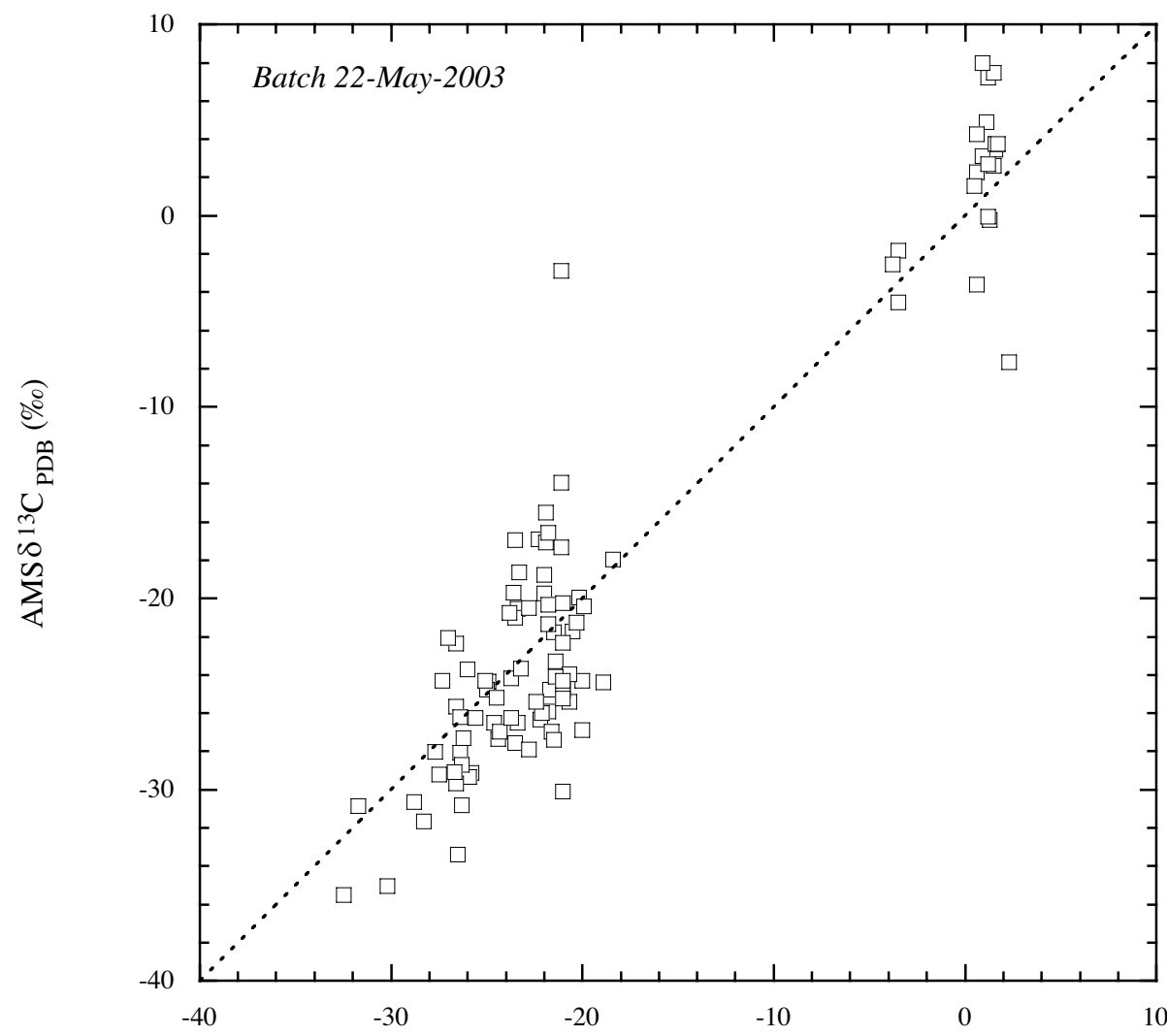

Dual inlet $\mathrm{MS} \delta^{13} \mathrm{C}_{\mathrm{PDB}}(\%)$

Figure 1 Comparison of $\delta^{13} \mathrm{C}$ values measured with the SUERC AMS system and dual inlet isotope mass spectrometer (IRMS)

\section{PRELIMINARY PERFORMANCE OF THE GAS ION SOURCE}

Although the full performance tests on the gas ion source have not yet been completed, a brief description of the gas ion source with the preliminary performance results are reported as follows. The $\mathrm{CO}_{2}$ sample is introduced into the 40 -sample ion source (S2) by the gas handling system (Figure 2). This handling system uses a manifold and gas flow control system, which applies in 10 individual gas sample containers (bellows). As the bellows $\left(116 \mathrm{~cm}^{3}\right)$ are much larger in volume than the manifold $\left(9 \mathrm{~cm}^{3}\right)$, it can be ensured that little of the gas is wasted when the common part of the manifold is evacuated before another gas sample is introduced. The manifold is connected to the source by a $0.25 \mathrm{~mm}$ i.d. capillary of $1.2 \mathrm{~m}$ length, giving a constant gas flow for a given pressure. The pressure is measured with a pressure transducer ( 400 mbar) and this is used to regulate the bellows' volume. 


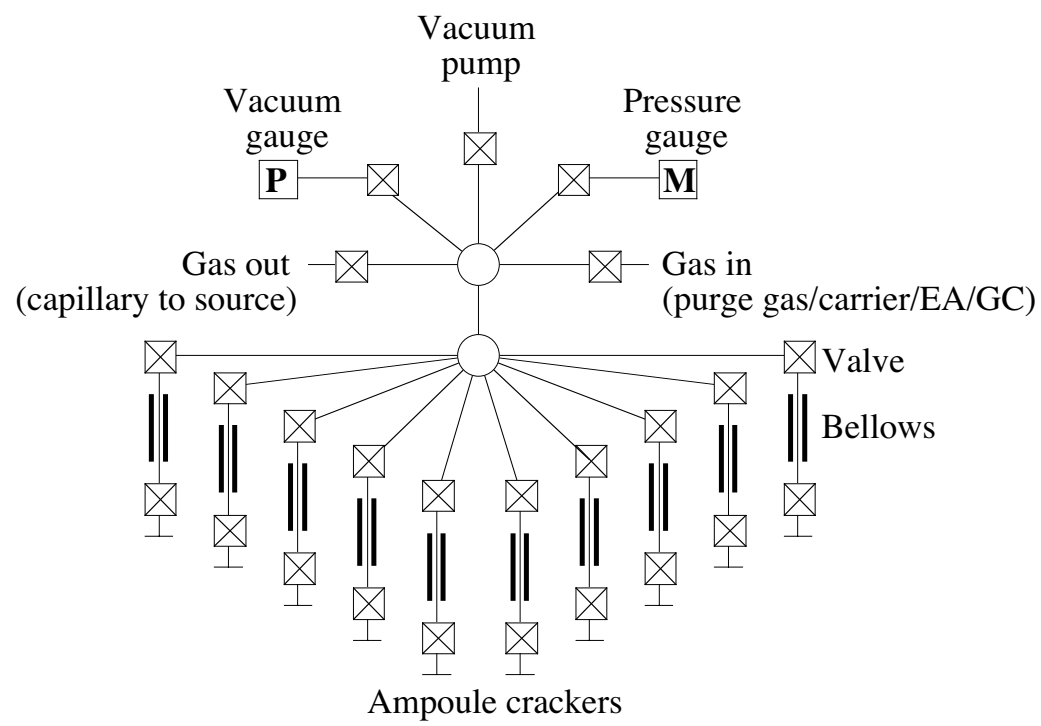

Figure 2 Diagram of the gas handling system

The sample holder used for the gas sample in the ion source is modified from that used for a solid sample by inserting a piece of titanium into the sample holder. The holders are fixed in the sample wheel where the gas tube is pressed on the back of the sample holder. The $\mathrm{CO}_{2}$ is directly fed through the gas tube to the holder where it is passed over and adsorbed onto the titanium; sputtering by the Cs beam generates negative ions of carbon and oxygen. The targets become sufficiently contaminated with the carbon from the gas so that they must be replaced for each sample.

In operation, gas flow and current stabilization were firstly performed in order to keep the source performance the same for each sample. A typical $10 \mu \mathrm{A}$ of $\mathrm{C}^{-}$could be extracted. To determine the $\mathrm{CO}_{2}$ to $\mathrm{C}^{-}$efficiency, we used about $250 \mu \mathrm{g}$ of carbon for a 2-hr measurement, stabilized at $6 \mu \mathrm{A}$. This represents an overall efficiency of about $2 \%$ for negative ion production. The background beam current, however, was less than $40 \mathrm{nA}$. These values are comparable to previous reports (e.g. Middleton et al. 1989; Ramsey and Hedges 1997).

In the first measurement with the ${ }^{12} \mathrm{C}^{-}$currents ranging from 7 to $10 \mu \mathrm{A}$ and an average accelerator $4+$ particle transmission of $57 \%$, the standard deviations $(1 \sigma)$ of the ${ }^{14} \mathrm{C} /{ }^{12} \mathrm{C}$ ratios for a single sample, 5 measurements for OxII and doublespar, and 3 for barley mash, were $0.6 \%, 18 \%$, and $1.1 \%$, respectively, which is comparable to the statistical uncertainties. On the other hand, the precision on the ${ }^{13} \mathrm{C} /{ }^{12} \mathrm{C}$ ratios for the 3 samples was $0.2-0.3 \%$. Encouragingly, these first results imply that precision for an individual sample is comparable between graphite and the gas source.

\section{CONCLUSION}

Since May 2003, the fully-automated and high-throughput SUERC AMS system has been used routinely for ${ }^{14} \mathrm{C}$ dating. Measurements with modern samples have shown that a precision of better than $0.3 \%$ is obtainable. The levels of background for the AMS machine together with the sample preparation process are generally $0.16 \mathrm{pMC}$, indicating a ${ }^{14} \mathrm{C}$ dating limit of $51 \mathrm{kyr}$. Further performance tests on the gas ion source are in progress. 


\section{ACKNOWLEDGEMENTS}

This work is supported by NERC JIF award (GR3/J0001): an AMS facility for ${ }^{14} \mathrm{C}$ and cosmogenic isotope applications. We are grateful to A Tait of SUERC and R Kitchen, G Klody, R Loger, M Sundquist of NEC for their assistance during the installation and normal operation of the SUERC AMS. We thank A Smith and R Sparks for their valuable reviews.

\section{REFERENCES}

Bonani G, Beer J, Hofmann H, Synal HA, Suter M, Wölfli W, Pfleiderer C, Kromer B, Junghans C. Münnich KO. 1987. Fractionation, precision and accuracy in ${ }^{14} \mathrm{C}$ and ${ }^{13} \mathrm{C}$ measurements. Nuclear Instruments and Methods in Physics Research B 29: 87-90.

Clercq ML, van der Plicht J, Gröning M. 1998. New ${ }^{14} \mathrm{C}$ reference materials with activities of 15 and $50 \mathrm{pMC}$. Radiocarbon 40(1):295-7.

Donahue DJ, Linick TW, Jull AJT. 1990. Isotope-ratio and background corrections for accelerator mass spectrometry radiocarbon measurement. Radiocarbon 32(2):135-42.

Freeman S, Bishop P, Bryant C, Cook G, Fallick A, Harkness D, Metcalfe S, Scott M, Scott R, Summerfield M. Forthcoming a. A new environmental sciences AMS laboratory in Scotland. Nuclear Instruments and Methods in Physics Research B.

Freeman S, Xu S, Schnabel C, Dougans A, Tait A, Kitchen R, Klody G, Loger R, Pollock T, Schroeder J, Sundquist M. Forthcoming b. Initial measurements

with the SUERC 5MV spectrometer. Nuclear Instruments and Methods in Physics Research B.

Gulliksen S, Scott EM. 1995. Report of the TIRI workshop, Saturday, 13 August 1994. Radiocarbon 37(2): $820-1$.

Middleton R, Klein J, Fink D. 1989. A $\mathrm{CO}_{2}$ negative ion source for ${ }^{14} \mathrm{C}$ dating. Nuclear Instruments and Methods in Physics Research B 43:231-9.

Ramsey CB, Hedges REM. 1997. Hybrid ion sources: radiocarbon measurements from microgram to milligram. Nuclear Instruments and Methods in Physics Research B 123:539-45.

Rozanski K, Stichler W, Gonfiantini R, Scott EM, Beukens RP, Kromer B, var der Plicht J. 1992. The IAEA ${ }^{14} \mathrm{C}$ intercomparison exercise 1990. Radiocarbon 34(3):506-19.

Scot EM. 2003. The Fourth International Radiocarbon Intercomparison (FIRI). Radiocarbon 45(2):135-291.

Slota PJ Jr, Jull AJT, Linick TW, Toolin LJ. 1987. Preparation of small samples for ${ }^{14} \mathrm{C}$ accelerator targets by catalytic reduction of CO. Radiocarbon 29(2):303-6. 